\title{
A rechargeable high-temperature molten salt iron-oxygen battery
}

Cheng Peng*1, Chengzhi Guan ${ }^{1}$, Jun Lin ${ }^{1}$, Shiyu Zhang ${ }^{1}$, Hongliang Bao ${ }^{1}$, Yu Wang ${ }^{1}$, Guoping Xiao ${ }^{1}$, George Zheng Chen*2, Jian-Qiang Wang*1

1 Department of Molten Salt Chemistry and Engineering, and Key Laboratory of Interfacial Physics and Technology, Shanghai Institute of Applied Physics, Chinese Academy of Sciences, Shanghai 201800, P. R. China

2 Department of Chemical and Environmental Engineering, Faculty of Engineering, University of Nottingham, University Park, Nottingham NG7 2RD, UK

Corresponding Email: pengcheng@sinap.ac.cn; george.chen@nottingham.ac.uk; wangjianqiang@sinap.ac.cn

\begin{abstract}
The energy and power density of conventional batteries are far lower than their theoretical expectations, primarily because of the slow reaction kinetics in the battery that is often working under ambient conditions. Here we describe a low-cost and high-temperature rechargeable iron-oxygen battery containing a bi-phase electrolyte of molten carbonate and solid oxide. This new design merges the merits of solid oxide fuel cell and molten metal-air battery, offering significantly improved battery reaction kinetics and hence the power capability without compromising the energy capacity. The as-fabricated battery prototype can be charged at high current density, and exhibit excellent stability and security in highly charged state without self-discharge. It typically exhibits $129.1 \mathrm{Wh} \mathrm{kg}^{-1}$ in specific energy and 2.8 $\mathrm{kW} \mathrm{kg}^{-1}$ in specific power, and $388.1 \mathrm{Wh} \mathrm{L}^{-1}$ in energy density and $21.0 \mathrm{~kW} \mathrm{~L}^{-1}$ in power density based on the mass and volume of the molten salt, respectively.
\end{abstract}

\section{Keywords}

high-temperature, rechargeable iron-oxygen battery, molten salt, yttria stabilized zirconia, electrochemical energy storage.

\section{Introduction}

With the rapidly growing demand for electrical vehicles and grid-scale energy stores, many efforts have been focused on the development of various electrochemical energy storage (EES) technologies, such as batteries, supercapacitors, and fuel cells. ${ }^{[1-3]}$ Among the myriad EES devices, rechargeable metaloxygen batteries offer the possibilities of high energy density and low cost, together with high safety and environmental compatibility. ${ }^{[4-8]}$ Currently, the major challenge to rechargeable metal-oxygen batteries resides in the sluggish kinetics of electrode reactions, resulting in low energy and power densities. ${ }^{[9-11]}$ Therefore, activation of the reactions of both the negative and positive electrodes is crucial for highperformance rechargeable metal-oxygen batteries.

Elevating the working temperature of metal-oxygen batteries could be an effective approach to reaction acceleration. Furthermore, many base metals including iron, tin and bismuth can be activated at high temperatures and thus utilized to lower the battery cost. One type of promising high-temperature metal-oxygen batteries is derived from high-temperature fuel cells. For instance, the high-temperature iron-oxide battery explores the iron redox reactions in a solid oxide fuel cell (SOFC) structure through a $\mathrm{H}_{2} / \mathrm{H}_{2} \mathrm{O}$ mediator, which performs higher discharge capacities in comparison with room-temperature 
iron-oxygen batteries. ${ }^{[12-15]}$ In analogy, molten tin and bismuth have served as the negative electrode materials in direct carbon fuel cells (DCFC) to integrate energy storage and power generation. ${ }^{[16-18]} \mathrm{In}$ such batteries, metal oxides can easily form at the interface between the metal and solid electrolyte, which impedes ion conductivity. Another type of high-temperature metal-oxygen battery is the so called molten air battery (MAB), which can use base metals for fast multiple electron charge transfer in molten salts. ${ }^{[19-21]}$ In a typical MAB, fast iron redox reactions in molten lithium carbonate were proposed as battery reactions for energy storage and conversion, with a high theoretical specific energy of $1400 \mathrm{Wh}$ $\mathrm{kg}^{-1}$ and energy density of $10000 \mathrm{Wh} \mathrm{L}^{-1}$. Of particular importance is that the molten salts in MAB have the capability to dissolve metal oxides. Herein, we propose and demonstrate a low-cost, rechargeable high-temperature molten salt iron-oxygen battery (MIB) with a bi-phase electrolyte of molten carbonate and solid oxide, which merges the merits of SOFC and MAB to promote battery reactions and achieve high energy and power density.

\section{Results}

\section{Battery fabrication}

The laboratory battery was constructed with a nickel negative electrode, an yttria stabilized zirconia (YSZ) supported silver positive electrode, and a hematite-containing molten salt electrolyte. In detail, an YSZ plate was sealed at one end of an alundum tube and filled with the mixture of hematite $(7.2 \mathrm{~g})$, lithium oxide $(2.7 \mathrm{~g})$ and lithium carbonate $(20.1 \mathrm{~g})$. Conductive silver paste was coated on the outside of the YSZ plate for connection with a silver wire to build the oxygen electrode with an apparent area of ca. $10 \mathrm{~cm}^{2}$ (Fig. S1). A coiled nickel wire (Fig. S2) with a specific surface area of $0.1170 \mathrm{~m}^{2} \mathrm{~g}^{-1}$ (Fig. S3) was then dipped in the hematite-contained molten salt as an inert electrode under a nitrogen atmosphere. At first, hematite powders were reacted with lithium oxide and formed $\mathrm{LiFeO}_{2}$, which was then dissolved in $\mathrm{Li}_{2} \mathrm{CO}_{3}$ under high-temperatures. During charge, $\mathrm{LiFeO}_{2}$ was reduced on the negative electrode and the reduction product $\mathrm{Fe}(0)$ was deposited on the surface of nickel wires, and simultaneously the oxide ions were conducted in the bi-phase electrolyte and then oxidized as oxygen on the positive electrode. Inversely, oxygen was reduced on the silver positive electrode during discharge, and the reduction product of oxide ions were conducted in the bi-phase electrolyte and then oxidized $\mathrm{Fe}(0)$ on the surface of nickel wires to the oxidation product of $\mathrm{LiFeO}_{2}$ which was dissolved in $\mathrm{Li}_{2} \mathrm{CO}_{3}$ (Fig. 1a). 

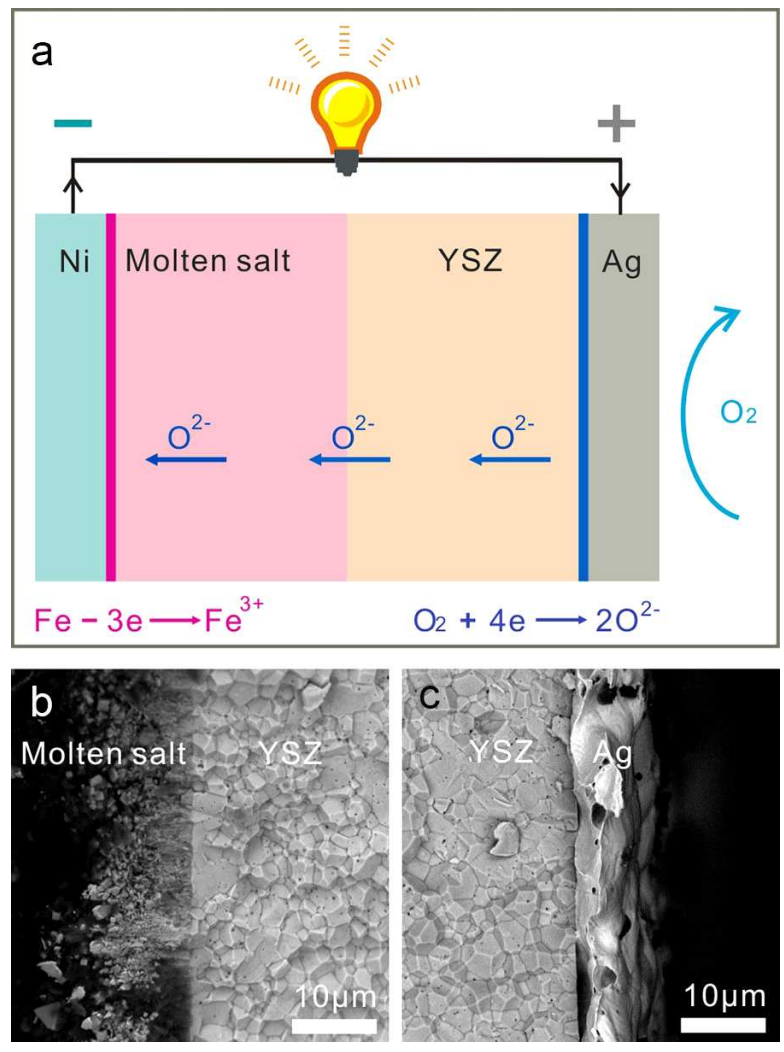

Figure 1. a) Schematic drawing of the MIB in the discharging mode in which metallic iron is oxidized and then dissolve in the molten salt on the negative electrode, oxygen molecules are reduced to oxide ions on the positive electrode. These reactions are reversed during charging. b) An SEM image showing the interface between molten salt and YSZ. c) An SEM image showing the interface between the silver electrode and YSZ.

In this new battery design, the nickel wire works as the negative electrode to enable fast iron redox reactions, the YSZ-supported silver oxygen electrode works as the positive electrode to help oxygen redox reaction, and the molten carbonate can dissolve hematite and, in conjunction with the YSZ plate, conduct oxide ions (Fig. 1b). At high temperatures, the YSZ plate has high oxide ion conductivity and insulate any electron flows. The scanning electron microscopy (SEM) image in Fig. 1c reveals a distinct interface between the YSZ plate and the molten salt, indicating that the YSZ plate is sufficiently dense and corrosion-resistant to avert molten salt percolation. Fig. S4 further depicts the similar K-edge X-ray absorption near-edge spectroscopy (XANES) spectra of $\mathrm{Zr}$ before and after 200 cycles of charge/discharge tests, ${ }^{[22]}$ indicating that the local structure around the $\mathrm{Zr}$ atom in YSZ is sufficiently stable for conduct oxide ions under the fairly harsh conditions in this study.

\section{Mechanism investigation}

We first explored the composition of solidified samples of the molten salt before and after charge/discharge cycling via X-ray diffraction (XRD). Fig. 2a presents the XRD pattern of the solidified salt before charge, exhibiting peaks at $2 \theta$ values of $37.6^{\circ}, 43.6^{\circ}, 63.3^{\circ} 76.1^{\circ}$ and $80.1^{\circ}$, which can be attributed to the crystal planes of (111), (200), (220), (311) and (222) in the pure cubic phase of lithium iron oxide $\left(\mathrm{LiFeO}_{2}\right)$, respectively, according to the reference pattern JCPDS cards 17-0938 and 22-1141. 
It indicates that after melting at $800{ }^{\circ} \mathrm{C}$, part of the mixture of hematite $\left(\alpha-\mathrm{Fe}_{2} \mathrm{O}_{3}\right)$ and lithium oxide $\left(\mathrm{Li}_{2} \mathrm{O}\right)$ transformed to $\mathrm{LiFeO}_{2}$. The other strong peaks in Fig. 2a, at $21.4^{\circ}, 30.7^{\circ}, 31.9^{\circ}, 34.2^{\circ}, 37.1^{\circ}, 48.8^{\circ}$, $56.9^{\circ}$ and $59.8^{\circ}$ can be tracked to lithium carbonate $\left(\mathrm{Li}_{2} \mathrm{CO}_{3}\right)$, indicating that $\mathrm{LiFeO}_{2}$ and $\mathrm{Li}_{2} \mathrm{CO}_{3}$ are the major constituents of the molten salt. Similarly, the XRD pattern (Fig. S5) demonstrates that the major constituent of molten salt after cycling charge/discharge were $\mathrm{LiFeO}_{2}$ and $\mathrm{Li}_{2} \mathrm{CO}_{3}$ as well, except for the slightly reduced peaks of $\mathrm{Li}_{2} \mathrm{CO}_{3}$ on account of consumption or decomposition at high temperatures.
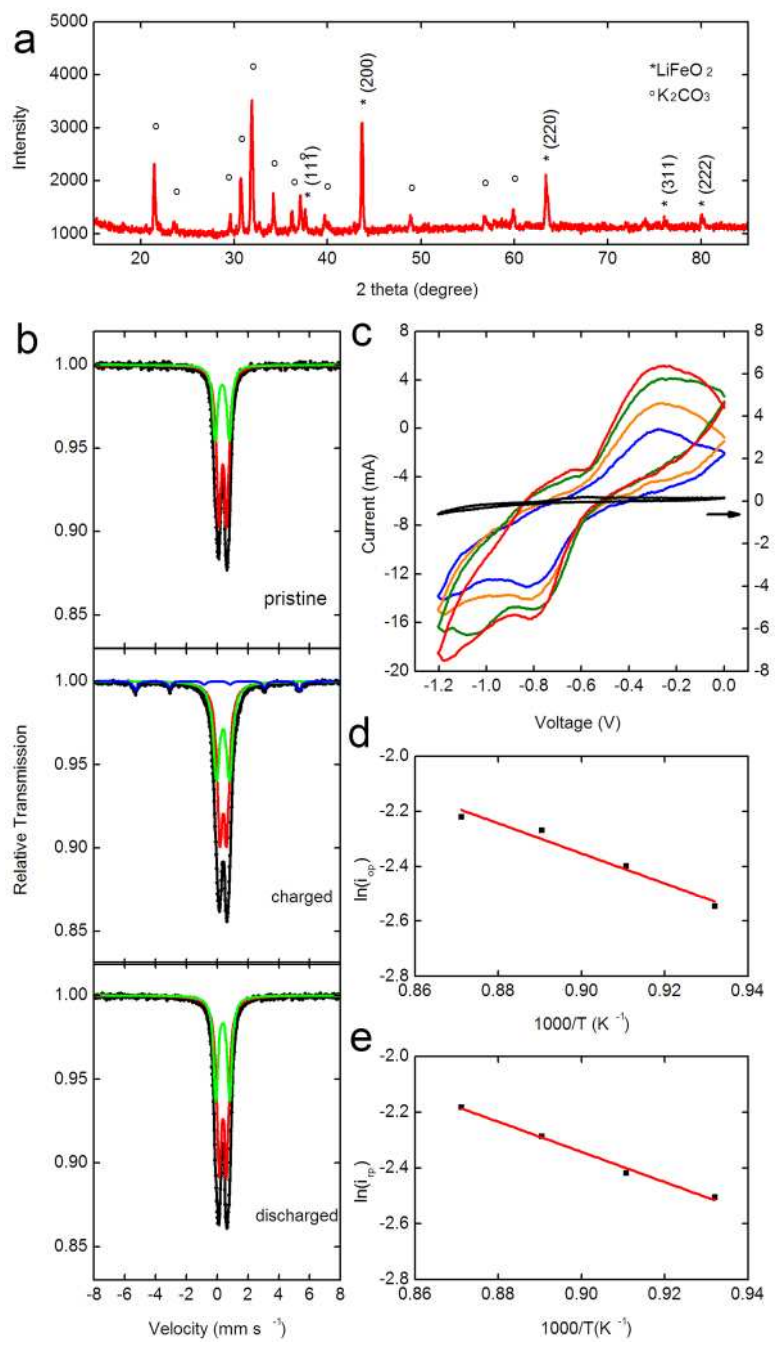

Figure 2. a) The XRD spectrum of solidified molten salt samples before charging. b) Mössbauer spectra of solidified molten salt samples of the pristine, charged and discharged natures, respectively. c) Cyclic voltammograms of hematite in lithium carbonate at $800{ }^{\circ} \mathrm{C}$ (blue), $825^{\circ} \mathrm{C}$ (olive), $850{ }^{\circ} \mathrm{C}$ (orange), $875{ }^{\circ} \mathrm{C}$ (red), respectively, and the cyclic voltammogram of lithium carbonate at $800{ }^{\circ} \mathrm{C}$ (black). d) The Arrhenius plot of electrochemical oxidation reactions. e. The Arrhenius plot of electrochemical reduction reactions.

We further investigated the composition of the solidified molten salt samples via Mössbauer analysis at room temperature. ${ }^{[23]}$ As shown in Fig. 2b, the Mössbauer spectra of molten salt at various stages were computer-fitted, assuming several hyperfine components made of absorption peaks with Lorentzian line shapes, and the detailed values of isomeric shift (IS), quadrupole splitting (QS) and magnetic hyperfine field (HF) are displayed in Table S1. According to the fitting results, the Mössbauer spectrum of pristine molten salt (melting but before charging-discharging) is comprised of two 
quadrupole doublets with a relative abundance of 66:34, suggesting two iron-containing phases with different coordination environments around Fe (III) atoms. Furthermore, the IS value of two components are 0.35 and $0.33 \mathrm{~mm} \mathrm{~s}^{-1}$, the QS value of two components are 0.51 and $0.92 \mathrm{~mm} \mathrm{~s}^{-1}$, confirming the two different iron-containing phases to be $O 3$-type $\mathrm{LiFeO}_{2}$ and ordered rocksalt type $\mathrm{LiFeO}_{2}$, respectively. In a particular note, the quadrupole doublet of zero-valence iron, i.e. Fe (0) emerged in the Mössbauer spectrum of molten salt during charge (the iron utilization of the hematite-contained molten salt was $21 \%$ ). It strongly suggests that $\mathrm{LiFeO}_{2}$ was reduced to $\mathrm{Fe}(0)$. However, the XRD pattern of the same sample (Fig. S6) demonstrates that none of the obvious diffraction peak was corresponding to Fe (0), it might be attributed to the relatively low concentration of reduction product in such partially charged state. In addition, the XRD pattern of the molten salt in a fully charged state (Fig. S7) demonstrates the diffraction peaks of $\mathrm{LiFeO}_{2}$ were vanished, indicating $\mathrm{LiFeO}_{2}$ were thoroughly reduced. Importantly, the peaks at $2 \theta$ values of $42.8^{\circ}$ and $50.3^{\circ}$ should be attributed to the crystal planes of (111) and (200) in the cubic phase of iron, respectively, according to the reference pattern JCPDS card 65-4150. It further implies that $\mathrm{LiFeO}_{2}$ was reduced to $\mathrm{Fe}(0)$. Moreover, the relative abundance of $O 3$-type $\mathrm{LiFeO}_{2}$ and ordered rocksalt type $\mathrm{LiFeO}_{2}$ were decreased to 53:42, suggesting that the $O 3$-type $\mathrm{LiFeO}_{2}$ phase was decreased whereas the ordered rocksalt type $\mathrm{LiFeO}_{2}$ phase was increased during charge. However, the quadrupole doublet of Fe (0) disappeared in the Mössbauer spectrum of molten salt when the MIB was discharged. It suggests that the $\mathrm{Fe}(0)$ was oxidized to $\mathrm{LiFeO}_{2}$ during discharge. Besides, the relative abundance of $O 3$-type $\mathrm{LiFeO}_{2}$ and ordered rocksalt type $\mathrm{LiFeO}_{2}$ was increased to 63:37, suggesting the O3-type $\mathrm{LiFeO}_{2}$ phase was increased whereas the ordered rocksalt type $\mathrm{LiFeO}_{2}$ phase was decreased during discharge. Therefore, it can be concluded that the charge-discharge processes of the MIB correspond to the redox conversion between $\mathrm{Fe}(0)$ and $\mathrm{LiFeO}_{2}$.

We next studied the redox conversion between $\mathrm{Fe}(0)$ and $\mathrm{LiFeO}_{2}$ using cyclic voltammetry $(\mathrm{CV})$ in a three electrode cell at different temperatures. CV curves in Fig. 2c show a pair of well-defined redox peaks in the range from $0.82 \mathrm{~V}$ to $0.28 \mathrm{~V}$, corresponding to the reversible redox conversion between $\mathrm{Fe}$ $(0)$ and $\mathrm{LiFeO}_{2}$. Furthermore, the peak currents of both oxidation $\left(i_{o p}\right)$ and reduction $\left(i_{r p}\right)$ on the $\mathrm{CV}$ curves remarkably increase with raising the temperature, implying that high temperature accelerates the reaction rates of both oxidation and reduction. Based on the peak currents at different temperatures, Arrhenius plots were drawn to evaluate the activation energy. In oxidation, the slope of the Arrhenius plot was 5.47 (with an Adj. R-Square value of 95.0\%), leading to a value of $104.73 \mathrm{~kJ} \mathrm{~mol}^{-1}$ in activation energy (Fig. 2d). Likewise, the value of activation energy in reduction was found to be $103.59 \mathrm{~kJ} \mathrm{~mol}^{-1}$, calculated from the slope of the Arrhenius plot (5.41) with an Adj. R-Square value of 98.9\% (Fig. 2e). According to the Arrhenius Equation, the rate constants of oxidation and reduction at $850{ }^{\circ} \mathrm{C}$ were 1.69 times and 1.67 times larger than those at $800^{\circ} \mathrm{C}$, respectively.

\section{Battery performances}

To evaluate the performance of the MIB, we generated the Ragone plots via charge/discharge cycling in a mode of constant current charging and constant power discharging (Fig. S8). When discharging at a constant power of $0.1 \mathrm{~W}$ at $800{ }^{\circ} \mathrm{C}$, the MIB exhibited a specific energy of $129.4 \mathrm{Wh} \mathrm{kg}^{-}$ ${ }^{1}$ and a specific power of $2.8 \mathrm{~kW} \mathrm{~kg}^{-1}$ based on the mass of the molten salt, corresponding to $770.2 \mathrm{Wh}$ $\mathrm{kg}^{-1} \mathrm{Fe}(0)$ and $16.7 \mathrm{~kW} \mathrm{~kg}^{-1} \mathrm{Fe}(0)$ based on the mass of active $\mathrm{Fe}(0)$, respectively. When the MIB was discharged at a constant power of $0.25 \mathrm{~W}$ at $800{ }^{\circ} \mathrm{C}$, the specific energy decreased to $92.0 \mathrm{Wh} \mathrm{kg}^{-1}(547.6$ $\mathrm{Wh} \mathrm{kg}^{-1} \mathrm{Fe}(0)$ ) while the specific power increased to $7.0 \mathrm{~kW} \mathrm{~kg}^{-1}\left(41.7 \mathrm{~kW} \mathrm{~kg}^{-1} \mathrm{Fe}(0)\right)$. However, the MIB offered a higher specific energy of $148.6 \mathrm{Wh} \mathrm{kg}^{-1}\left(884.5 \mathrm{Wh} \mathrm{kg}^{-1} \mathrm{Fe}(0)\right)$ and $113.6 \mathrm{Wh} \mathrm{kg}^{-1}\left(676.2 \mathrm{Wh} \mathrm{kg}^{-}\right.$ 
${ }^{1} \mathrm{Fe}(0)$ ) when operating at $850{ }^{\circ} \mathrm{C}$ with the discharge of constant power at $0.1 \mathrm{~W}$ and $0.25 \mathrm{~W}$, respectively. In comparison with other EES devices (Fig. 3a), the specific energy of MIB under $800{ }^{\circ} \mathrm{C}$ and $850{ }^{\circ} \mathrm{C}$ is competitive against lead-acid batteries, nickel metahydride batteries or lithium ion batteries, whilst the specific power of MIB is competitive against some supercapacitors. ${ }^{[24-26]}$

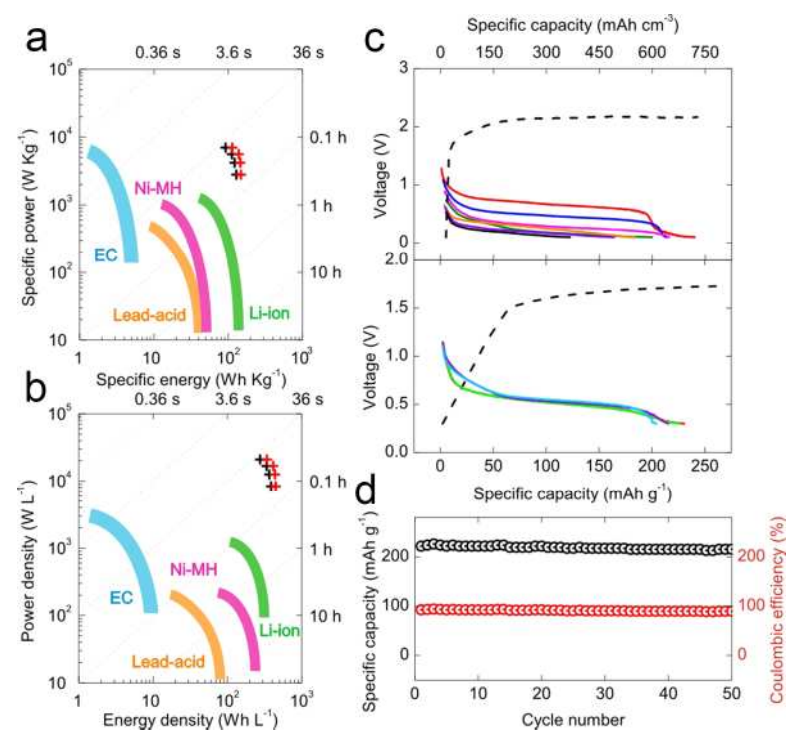

Figure 3. a, b) Ragone plots of the MIB on gravimetric (a) and volumetric (b) bases at $800{ }^{\circ} \mathrm{C}$ (black cross) and $850{ }^{\circ} \mathrm{C}$ (red cross) and common EES devices as indicated. c) The discharging curves of the MIB at different currents: 0.1 (red), 0.3 (blue), 0.5 (magenta), 0.7 (green), 0.9 (orange), 1.1 (violet) and 1.3 A (black) with the charging curve (black dash) at a current of $1.0 \mathrm{~A}$ (up), and the discharging curves of the MIB at $0.1 \mathrm{~A}$ in the 1st (red), 2nd (green), 50th (violet) and 100th (blue) cycles with the charging curve (black dash) at 1.0 A (down). d) Variation of specific capacity (black) and coulombic efficiency (red) of the MIB in the first 50 galvanostatic cycles.

Considering that the volume of $30 \mathrm{~g}$ molten salt was only about $10 \mathrm{~cm}^{-3}$ after melting above $800{ }^{\circ} \mathrm{C}$, we further generated the Ragone plot on the volumetric basis to evaluate the performance of the MIB (Fig. S9). Specifically, the energy density derived from discharging at a constant power of $0.1 \mathrm{~W}$ was 388.1 $\mathrm{Wh} \mathrm{L}^{-1}$ and $445.7 \mathrm{Wh} \mathrm{L}^{-1}$ at $800{ }^{\circ} \mathrm{C}$ and $850{ }^{\circ} \mathrm{C}$, respectively. When raising the discharging power to $0.25 \mathrm{~W}$, the energy density of the MIB decreased to $276.1 \mathrm{Wh} \mathrm{L}^{-1}$ and $340.7 \mathrm{Wh} \mathrm{L}^{-1}$ at $800{ }^{\circ} \mathrm{C}$ and $850{ }^{\circ} \mathrm{C}$, respectively. However, the power density increased from $8.4 \mathrm{~kW} \mathrm{~L}^{-1}$ to $21.0 \mathrm{~kW} \mathrm{~L}^{-1}$. Compared with the other EES devices in Fig. 3b, the merits of the MIB on the volumetric basis is more evident in power density, ${ }^{[24]}$ due to obviously the high density of molten salt.

In order to investigate the specific capacity of the MIB, we then carried out galvanostatic chargedischarge (GCD) tests with the cutoff voltage of 0.1 V. Fig. 3c shows typical GCD profiles of the MIB at different discharging currents at $800{ }^{\circ} \mathrm{C}$. At $0.1 \mathrm{~A}$, the measured specific capacity was $240.0 \mathrm{mAh} \mathrm{g}^{-1}$ based on the molten salt mass, which is $97.2 \%$ of the full charge capacity. Furthermore, a pronounced voltage plateau locates in the voltage range of 0.8 and $0.6 \mathrm{~V}$, which could be attributed to the oxidation of $\mathrm{Fe}(0)$ to $\mathrm{LiFeO}_{2}$. As the discharge current increased from $0.1 \mathrm{~A}$ to $1.3 \mathrm{~A}$, the charge capacity of the MIB decreased from $240.0 \mathrm{mAh} \mathrm{g}^{-1}$ to $122.3 \mathrm{mAh} \mathrm{g}^{-1}$, or from $720.0 \mathrm{mAh} \mathrm{cm}^{-3}$ to $366.9 \mathrm{mAh} \mathrm{cm}^{-3}$ on the basis of molten salt. As a result, the voltage of plateau decreased as well. The MIB was also studied by galvanostatic charge-discharge cycling at $800{ }^{\circ} \mathrm{C}$ with a cutoff voltage of $0.3 \mathrm{~V}$. Fig. $3 \mathrm{~d}$ presents the 
specific capacity decays from initially $230.5 \mathrm{mAh} \mathrm{g}^{-1}\left(691.5 \mathrm{mAh} \mathrm{cm}^{-3}\right)$ to $204.4 \mathrm{mAh} \mathrm{g}^{-1}(613.2 \mathrm{mAh}$ $\mathrm{cm}^{-3}$ ) after 100 cycles, corresponding to a low capacity fading rate of less than $11.3 \%$. Moreover, the coulombic efficiency (CE) decreased to $84.5 \%$ after 50 cycles, a little lower than $92.7 \%$ of the first cycle (Fig. 3e).

\section{Battery characteristics}

During galvanostatic charge-discharge tests, we observed that the CE and Energy efficiency (EE) of the MIB were closely related with the discharging conditions, e.g. the cutoff voltage and discharging current. We first investigated the influence of cutoff voltage using a mode of constant charging current at $1 \mathrm{~A}$ and a constant discharging current at $0.1 \mathrm{~A}$ at $800{ }^{\circ} \mathrm{C}$ (Fig. 4a). When we charged MIB at $1 \mathrm{~A}$ for $30 \mathrm{~s}$, the iron utilization $\left(U_{F e}\right)$ of the hematite-contained molten salt was $\sim 0.35 \%$. Fig. S10 presents the value of $U_{F e}$ at different cutoff voltage during discharge. When the cutoff voltage increased from $0.1 \mathrm{~V}$ to $0.7 \mathrm{~V}$, the iron utilization decreased from $\sim 0.34 \%$ to $\sim 0.04 \%$, respectively. According to the theoretical specific capacity was $\sim 1430 \mathrm{mAh} \mathrm{g}^{-1}$, the charging current of $1 \mathrm{~A}$ and the discharging current of $0.1 \mathrm{~A}$ were equivalent to $\mathrm{C} / 1.4$ and $\mathrm{C} / 14$ rates, respectively. When the cutoff voltage increased from $0.1 \mathrm{~V}$ to $0.7 \mathrm{~V}$, the value of $\mathrm{CE}$ decreased from $95.2 \%$ to $11.4 \%$, and correspondingly the value of EE decreased from $20.7 \%$ to $3.9 \%$. It indicates that the charge and energy are gradually released with the descending discharging voltage. We then investigated the influence of the discharging current on both $\mathrm{CE}$ and $\mathrm{EE}$ in a mode of charging at $\mathrm{C} / 1.4$ rate with a cutoff voltage of $0.1 \mathrm{~V}$ (Fig. 4b). When the discharging current increased from $\mathrm{C} / 14$ to $\mathrm{C} / 1.1$ rate (corresponding to the increase of discharging current from 0.1 A to 1.3 A), the value of CE decreased from $98.1 \%$ to $49.4 \%$, and the corresponding value of EE decreased from $24.7 \%$ to $5.0 \%$. It suggests that a lower discharging current benefits the release of both charge and energy in the MIB. Beside the discharging conditions, the charging current influences the CE and EE of the MIB as well. We next investigated the influence of the charging current in a mode of discharging at $\mathrm{C} / 14$ rate with a cutoff voltage of $0.3 \mathrm{~V}$. As shown in Fig. 4c, the value of CE increased from $74.2 \%$ to $91.6 \%$ when the charging current increased from $\mathrm{C} / 4.8$ to $\mathrm{C} / 2.9$ rate (corresponding to the increase of charging current from $0.3 \mathrm{~A}$ to $0.5 \mathrm{~A}$ ), and remained at around $90 \%$ when charging at $\mathrm{C} / 1.6$ rate (equals to a constant charging current of $0.9 \mathrm{~A}$ ). However, the value of EE reached $36.9 \%$ when charging at $\mathrm{C} / 2.1$ rate (equals to a constant charging current of $0.7 \mathrm{~A}$ ), whereas it decreased to $27.8 \%$ when charging at $\mathrm{C} / 1.6$ rate. It indicates that an overlarge charge current depresses the value of EE. Additionally, the variations of CE and $\mathrm{EE}$ were studied when discharging at different powers in a mode of charging at $\mathrm{C} / 1.4$ rate with a cutoff voltage of $0.3 \mathrm{~V}$. Fig $4 \mathrm{~d}$ shows that the value of CE decreases from $80.3 \%$ to $50.2 \%$ and that of EE decreases from $25.0 \%$ to $18.8 \%$, when the discharge power increases from $0.1 \mathrm{~W}$ to $0.25 \mathrm{~W}$. It indicates that excessively increasing discharge power would decrease the values of both $\mathrm{CE}$ and $\mathrm{EE}$.

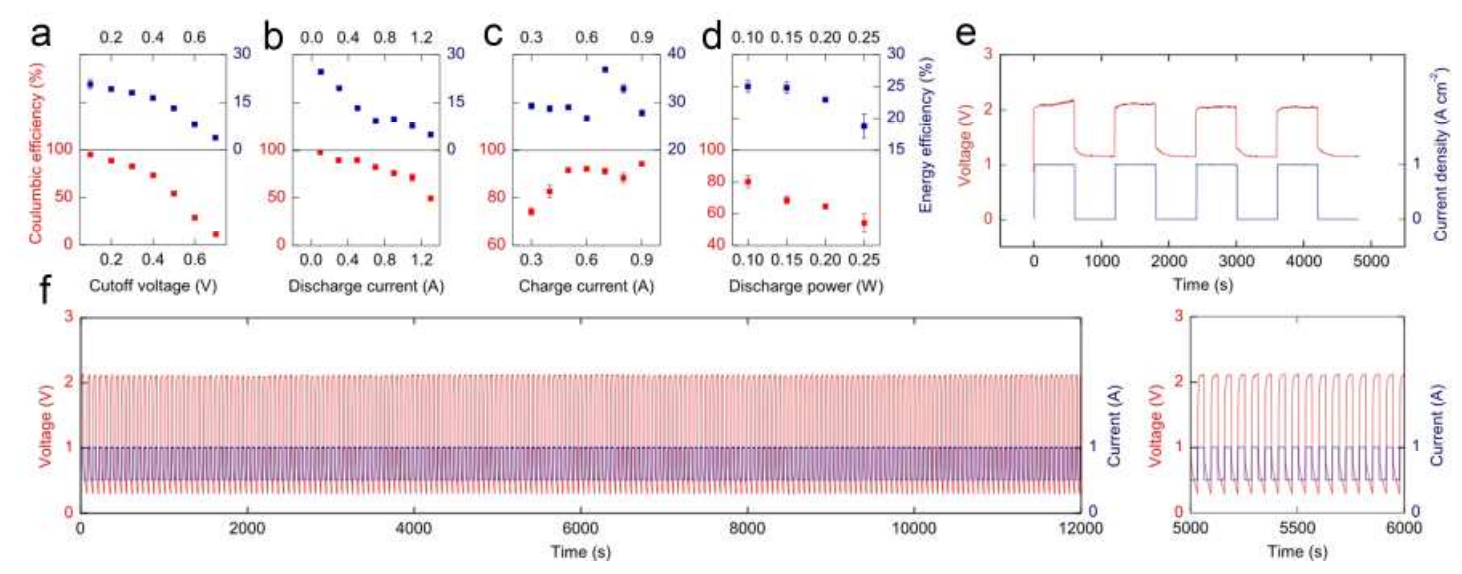


Figure 4. a) Coulombic and energy efficiencies of the MIB at different cutoff voltages. b) Coulombic efficiency of the MIB at different discharging currents. c) Coulombic efficiency of the MIB at different charging currents. d) Coulombic efficiency of the MIB at different discharging powers. e) The voltagetime profile of the MIB recorded during cycling between charging $\left(1.0 \mathrm{~A} \mathrm{~cm}^{-2}\right)$ and open circuit at $800{ }^{\circ} \mathrm{C}$ in nitrogen. f) Long-term stability of the MIB at 1.0 A charging and $0.5 \mathrm{~A}$ discharging currents and a cutoff voltage of $0.3 \mathrm{~V}$ over 200 cycles (left), with the magnified image from $5000 \mathrm{~s}$ to $6000 \mathrm{~s}$ (right).

Subsequently, we tested the stability of MIB by charging at high current densities. To obtain high current density, we replaced the commercial YSZ plate by a self-prepared $0.8 \mathrm{~mm}$-thick YSZ plate and the area of silver electrode was reduced from $10 \mathrm{~cm}^{2}$ to $0.5 \mathrm{~cm}^{2}$. As shown in Fig. 4e, after charging at $1.0 \mathrm{~A} \mathrm{~cm}^{-2}$ for $10 \mathrm{~min}$. at $800{ }^{\circ} \mathrm{C}$ in nitrogen, the open circuit voltage of the MIB anchors at ca. $2.1 \mathrm{~V}$, and this behavior remains almost the same when the measurement was repeated for many cycles. It shows clearly the high stability of the MIB during charging at a high current density. Moreover, a test of 200 charge-discharge cycles was applied to the MIB when the area of the silver electrode was $10 \mathrm{~cm}^{-2}$, charging was carried out at $1.0 \mathrm{~A}$ for $30 \mathrm{~s}$, and discharging at $0.5 \mathrm{~A}$ with a cutoff voltage of $0.3 \mathrm{~V}$ under $800{ }^{\circ} \mathrm{C}$. Fig. $4 \mathrm{f}$ shows the recorded voltage-time profile, showing surprisingly a maximum voltage remaining at $2.1 \mathrm{~V}$ with the oscillation being less than $1 \%$ over the 200 cycles, further suggesting the exceptional stability of the MIB. Additionally, we recorded the voltage-time profile and the current-time profile of the MIB (the area of the silver electrode was $0.5 \mathrm{~cm}^{2}$ ) during charge at $0.5 \mathrm{~A}$ for $30 \mathrm{~s}$ and open circuit for $1 \mathrm{~h}$ after at $800{ }^{\circ} \mathrm{C}$ in nitrogen. As shown in Fig. S11, the open circuit voltage was gradually decreased from $1.41 \mathrm{~V}$ to $0.59 \mathrm{~V}$ in $1 \mathrm{~h}$, and the maximal value of the current was $3.72 \mu \mathrm{A}$. It should be attributed to the self-discharge of MIB. We speculate that such self-discharge was primarily due to the corrosion and permeation of molten salt, which could possibly bring the oxygen leakage from the sealing of MIB.

\section{Discussion}

The new MIB consists of a Ni inert electrode, an oxygen/Ag/YSZ electrode and a hematitecontaining molten salt electrolyte. Some ideas of the MIB were separately utilized in other EES devices such as the MAB and the liquid metal solid oxide fuel cell (LM-SOFC). ${ }^{[16,19]}$ However, compared with the MAB, the MIB employs the oxygen/Ag/YSZ electrode to substitute the metal/air electrode for accelerating electrode reactions and hence for improve the battery performance. ${ }^{[27,28]}$ Furthermore, the MIB uses a molten salt that is capable of conducting oxide ions and dissolving metal oxides. As a result, the metal oxide formed during discharge dissolves in the molten salt, rather than aggregates at the interface between the solid electrolyte and the metal negative electrode and impedes ion conductivity as in the LM-SOFC. Moreover, unlike the lithium ion battery (LIB) and sodium-sulfur (Na-S) battery, ${ }^{[29-31]}$ the YSZ plate in the MIB conducts oxide ions rather than metallic ions (i.e. $\mathrm{Li}^{+}$and $\mathrm{Fe}^{3+}$ ), thus avoids the formation of metal dendrites caused by metallic ion diffusion. Meanwhile, the electrochemically active species in the $\mathrm{MIB}$ are $\mathrm{Fe}(0)$ and $\mathrm{LiFeO}_{2}$, both of them are nonflammable, nontoxic, and environmentally friendly. In addition, the thickness of YSZ plate correlates closely with the resistance of the MIB. Thus, reducing the YSZ plate thickness helps to decrease the resistance and improve the overall performance of the MIB.

The most striking advantage of MIB is that high specific energy can be simultaneously achieved along with high specific power. The specific energy of the MIB is comparable to that of the LIB and whilst the specific power of the MIB matches that of electrochemical capacitors. Such performance 
characteristics of MIB closely resemble supercapbatteries. ${ }^{[10,32]}$ Undoubtedly, the superior performance of the MIB derives from the ultrafast redox reactions at high temperatures. Note that the surface area of negative electrode in the MIB is far less than that of carbon-based electrodes in supercapbatteries. ${ }^{[24-26]}$ It indicates that increasing the surface area of electrodes would further improve the MIB performances. On the other hand, the redox reaction in the molten salt is between $\mathrm{Fe}(0)$ and $\mathrm{Fe}$ (III) without involvement of Fe (II). Such a relatively uncomplicated electrochemical process favors the high performance of the MIB as well. On the basis of specific energy, the costs of molten salt can be estimated to be US\$ 112.1 $\mathrm{kWh}^{-1}$ and US\$ $97.6 \mathrm{kWh}^{-1}$ at $800{ }^{\circ} \mathrm{C}$ and $850{ }^{\circ} \mathrm{C}$, respectively, which are comparable to the costs of electrode materials in liquid metal batteries. ${ }^{[33-35]}$ When inexpensive carbonates such as sodium carbonate $\left(\mathrm{Na}_{2} \mathrm{CO}_{3}\right)$, potassium carbonate $\left(\mathrm{K}_{2} \mathrm{CO}_{3}\right)$ and potassium chloride $(\mathrm{KCl})$ were substituted for $\mathrm{Li}_{2} \mathrm{CO}_{3}$, the cost of molten salt would be significantly decreased..$^{[20,21]}$ This is another advantage of the MIB compared to other electrochemical energy storage devices.

\section{Conclusion}

In summary, we have developed a low-cost rechargeable high-temperature molten salt iron-oxygen battery (MIB) with high energy capacity and power capability, using a bi-phase electrolyte of molten salt and solid oxide membrane to conduct oxide ions. Typically at $800{ }^{\circ} \mathrm{C}$, the present battery can afford the following advantages compared with existing EES devices: (1) a specific energy of $129.1 \mathrm{Wh} \mathrm{kg}^{-1}$ and a specific power density of $2.8 \mathrm{~kW} \mathrm{~kg}^{-1}$ based on the mass of molten salt, (2) an energy density of 388.1 Wh L $\mathrm{L}^{-1}$ and a power density of $21.0 \mathrm{~kW} \mathrm{~L}^{-1}$ based on the volume of molten salt, (3) a specific capacity of $240.0 \mathrm{mAh} \mathrm{g}^{-1}$ based on the molten salt mass, a volumetric capacity of $720.0 \mathrm{mAh} \mathrm{cm}^{-3}$ based on the molten salt volume when discharging at $0.1 \mathrm{~A}$, (4) a superior stability to prevent self-discharge and excellent security at large charging current density, and (5) the cost of molten salt US\$112.1 kWh $\mathrm{kW}^{-1}$ at $800{ }^{\circ} \mathrm{C}$. Therefore, we anticipate this new battery has a great potential application in the area of gridscale energy storage.

\section{Experimental section}

Battery fabrication. The nickel negative electrode was fabricated by twisting and coiling six nickel wires (Jinchang Alloy Co. Ltd., Shanghai, China) with the diameter of $0.5 \mathrm{~mm}$. YSZ plate (5 mol\%) with the thickness of $0.5 \mathrm{~mm}$ was purchased from Haide ceramic company, Shenzhen, China, and YSZ plate ( $8 \mathrm{~mol} \%$ ) with the thickness of $0.8 \mathrm{~mm}$ was prepared by direct tablet compressing $8 \mathrm{~mol} \%$ YSZ powders (Tianrao Industrial Co. Ltd., Qingdao, China) after annealing treatment at $800{ }^{\circ} \mathrm{C}$ for $3 \mathrm{~h}$ and at $1400{ }^{\circ} \mathrm{C}$ for $2 \mathrm{~h}$. The silver positive electrode was fabricated by coating conductive silver paste (Shanghai research institute of synthetic resins, Shanghai, China) on one side of YSZ plate, two silver wires with the diameter of $1 \mathrm{~mm}$ were twisted and then stuck on silver positive electrode after drying at $150{ }^{\circ} \mathrm{C}$. One end of alumina tube was sealed by YSZ plate with high-temperature sealant (Ceramabond 552, AREMCO Products, Inc., US). The molten salt electrolyte was composed of lithium carbonate (20.1 g) lithium oxide $(2.7 \mathrm{~g})$ and iron oxide $(7.2 \mathrm{~g})$, and was contained in the one end-sealed alumina tube (with the inner diameter of $35 \mathrm{~mm}$ ). Finally, a battery was completed after putting nickel negative electrode in alumina tube. The whole battery was placed in an oven (made by Hefei Kejing materials technology Co., Ltd., China) which provides constant high temperatures. During charge/discharge, nitrogen flowed in alumina tube and oxygen flowed on silver electrode outside alumina tube, both of their flow rates were $30 \mathrm{~mL}$ $\mathrm{min}^{-1}$. Lithium oxide and lithium carbonate of A.R. grade were purchased from Aladdin reagent (Shanghai) Co., Ltd., China, and hematite of A.R. grade was purchased from Sigma-Aldrich Co., Ltd., 
China.

Electrochemical experiments. The battery with the silver-coating area of $10 \mathrm{~cm}^{2}$ was investigated in the mode of recycling constant current charge at $1 \mathrm{~A}$ within $30 \mathrm{~s}$ and constant power discharge at $0.1 \mathrm{~W}$, $0.15 \mathrm{~W}, 0.2 \mathrm{~W}, 0.25 \mathrm{~W}$, respectively, to calculate the specific energy and power. Considering that the electroactive species are dissolved or dispersed in molten salt, we calculate the performance of MIB in the mass or volume of molten salt. In detail, the weight of active iron metal was calculated by the theoretical values of iron metal that produced by the reduction of hematite under the charge current at 1 A within $30 \mathrm{~s}$, and the weight of molten salt was calculated by the theoretical values of the reduced hematite with the corresponding lithium carbonate and lithium oxide, for example, when $7.2 \mathrm{~g}$ hematite were reduced to $5.04 \mathrm{~g}$ iron, the weight of active iron metal was $5.04 \mathrm{~g}$, and the weight of molten salt was $30 \mathrm{~g}$. The volume of molten salt was measured via a fast draining method after a process of melting molten salt under $800{ }^{\circ} \mathrm{C}$ and then rapid cooling at room temperature. The columbic efficiency was evaluated by the ratio of charge/discharge electric quantities which were calculated by integrating the charge/discharge current per second. The energy efficiency was evaluated by the ratio of charge/discharge energies which were calculated by integrating the product of charge/discharge current and voltage per second. All the electrochemical experiments were performed on Maccor 4200 automated test system.

Cyclic voltammetry curves were scanned from $0 \mathrm{~V}$ to $-1.2 \mathrm{~V}$ with the scanning rate of $20 \mathrm{mV} \mathrm{s}^{-1}$ by Princeton 4000+ electrochemical workstation at different temperatures. Platinum wires with the diameter of $0.5 \mathrm{~mm}$ (Sigma-Aldrich Co., Ltd., China) were employed as the work electrode and counter electrode. All the experiments were executed in air.

Materials characterization. The scanning electron microscopy (SEM) images of the interfaces between Ag positive electrode/YSZ plate/molten salt were collected by Phenom ProX (Phenom China), using back scattering mode under the voltage of $10 \mathrm{kV}$. The surface area of $\mathrm{Ni}$ wires before battery cycling charge/discharge tests was measured by mercury porosimeter (Quantachrome Instruments), via an intrusion test with the pressure increasing from 0 PSI to 20000 PSI and an extrusion test with the pressure decreasing from 20000 PSI to 0 PSI. The X-ray absorption near-edge spectroscopy (XANES) data were collected on Beamline BL14W1 at the Shanghai Synchrotron Radiation Facility (SSRF). A double Si (111) crystal monochromator was employed for energy selection. High-order harmonics were successfully inhibited using a harmonic suppression mirror. K-edge XANES data of Zr atoms in YSZ before and after cycling charge/discharge tests were acquired in fluorescence mode via a Lytle detector, and the software package of Ifeffit was employed to analyze XANES data. X-ray diffraction spectra (XRD) were carried out with an X-ray diffractometer (Bruker AXS, D8 Advanced) using Cu Ka radiation $(\lambda=1.5418 \AA)$. Mössbauer spectra were measured using a constant acceleration transmission mode with ${ }^{2}{ }^{57} \mathrm{Co} / \mathrm{Rh}$ source at room temperature. The velocity was calibrated with a $25 \mu \mathrm{m} \alpha$-Fe foil, and the Isomer Shift (IS) was relative to the center of $\alpha$-Fe at room temperature. The spectra were fitted with the software of MossWinn.

Cost calculation. The cost of molten salt was calculated by the ratio of cost and specific energy. The price of lithium oxide (US\$22.7 Kg $\mathrm{Kg}^{-1}$ ), lithium carbonate (US\$18.2 $\mathrm{Kg}^{-1}$ ), and hematite (US\$1.2 $\mathrm{Kg}^{-1}$ ) were offered from the industrial companies in China.

\section{Acknowledgements}

The XAFS spectra were collected on Beamline BL14W1 at SSRF. This work was supported by the "Strategic Priority Research Program" of Chinese Academy of Sciences (No. XDA02040600), the Key 
Project of Science and Technology of Shanghai (15DZ1200100) and the National Natural Science Foundation of China (No. U1532259).

\section{Conflict of interest}

The authors declare no conflict of interest.

\section{Supporting Information}

Photograph of samples, SEM image, surface area data, EXANE spectra, XRD spectra, Ragone plots and detailed Mössbauer data.

\section{References}

[1] Z. G. Yang, J. L. Zhang, M. C. W. Kintner-Meyer, X. C. Lu, D. W. Choi, J. P. Lemmon, J. Liu, Chem. Rev. 2011, 111, 3577-3613.

[2] H. D. Yoo, E. Markevich, G. Salitra, D. Sharon, D. Aurbach, Mater. Today 2014, 17, 110-121.

[3] M. S. Whittingham, MRS Bull. 2008, 33, 411-419.

[4] J. Kim, H. Park, B. Lee, W. M. Seong, H. D. Lim, Y. Bae, H. Kim, W. K. Kim, K. H. Ryu, K. Kang, Nat. Commun. 2016, 7, 10334.

[5] M. C. Lin, M. Gong, B. G. Lu, Y. P. Wu, D. Y. Wang, M. Y. Guan, M. Angell, C. X. Chen, J. Yang, B. J. Hwang, H. J. Dai, Nature 2015, 520, 324-328.

[6] T. Liu, M. Leskes, W. J. Yu, A. J. Moore, L. N. Zhou, P. M. Bayley, G. Kim, C. P. Grey, Science 2015, 350, 530-533.

[7] G. Li, X. L. Wang, J. Fu, J. D. Li, M. G. Park, Y. N. Zhang, G. Lui, Z. W. Chen, Angew. Chem. Int. Ed. 2016, 55, 4977-4982.

[8] A. Ponrouch, C. Frontera, F. Barde, M. R. Palacin, Nat. Mater. 2016, 15, 169-172.

[9] P. G. Bruce, S. A. Freunberger, L. J. Hardwick, J. M. Tarascon, Nat. Mater. 2012, 11, 19-29.

[10] D. P. Dubal, O. Ayyad, V. Ruiz, P. Gomez-Romero, Chem. Soc. Rev. 2015, 44, 1777-1790.

[11] X. Dong, L. Chen, J. Liu, S. Haller, Y. Wang, Y. Xia, Sci. Adv. 2016, 2, e1501038.

[12] A. Inoishi, S. Ida, S. Uratani, T. Okano, T. Ishihara, Phys. Chem. Chem. Phys. 2012, 14, 1281812822.

[13] N. S. Xu, X. Li, X. Zhao, J. B. Goodenough, K. Huang, Energy Environ. Sci. 2011, 4, 49424946.

[14] A. S. Rajan, S. Sampath, A. K. Shukla, Energy Environ. Sci. 2014, 7, 1110-1116.

[15] C. Zhang, K. Huang, ACS Energy Lett. 2016, 1, 1206-1211.

[16] A. Jayakumar, S. Lee, A. Hornes, J. M. Vohs, R. J. Gorte, J. Electrochem. Soc. 2010, 157, B365B369.

[17] H. Abernathy, R. Gemmen, K. Gerdes, M. Koslowske, T. Tao, J. Power Sources 2011, 196, 4564-4572.

[18] Y. Nabae, K. D. Pointon, J. T. S. Irvine, Energy Environ. Sci. 2008, 1, 148-155.

[19] S. Licht, B. C. Cui, J. Stuart, B. H. Wang, J. Lau, Energy Environ. Sci. 2013, 6, 3646-3657.

[20] S. Z. Liu, X. Li, B. C. Cui, X. J. Liu, Y. L. Hao, Q. Guo, P. Q. Xu, S. Licht, J. Mater. Chem. A 2015, 3, 21039-21043.

[21] B. C. Cui, S. Licht, J. Mater. Chem. A 2014, 2, 10577-10580.

[22] M. Newville, J. Synchrotron Radiat. 2001, 8, 322-324.

[23] Z. Klencsar, E. Kuzmann, A. Vertes, J. Radioanal. Nucl. Chem. 1996, 210, 105-118.

[24] T. Q. Lin, I. W. Chen, F. X. Liu, C. Y. Yang, H. Bi, F. F. Xu, F. Q. Huang, Science 2015, 350, 
1508-1513.

[25] P. Simon, Y. Gogotsi, Nat. Mater. 2008, 7, 845-854.

[26] Y. W. Zhu, S. Murali, M. D. Stoller, K. J. Ganesh, W. W. Cai, P. J. Ferreira, A. Pirkle, R. M. Wallace, K. A. Cychosz, M. Thommes, D. Su, E. A. Stach, R. S. Ruoff, Science 2011, 332, $1537-$ 1541.

[27] J. T. S. Irvine, D. Neagu, M. C. Verbraeken, C. Chatzichristodoulou, C. Graves, M. B. Mogensen, Nat. Energy 2016, 1, 15014.

[28] J. Nielsen, T. Jacobsen, Solid State Ionics 2008, 178, 1769-1776.

[29] K. B. Hueso, M. Armand, T. Rojo, Energy Environ. Sci. 2013, 6, 734-749.

[30] F. D. Han, J. Yue, X. L. Fan, T. Gao, C. Luo, Z. H. Ma, L. M. Suo, C. S. Wang, Nano Lett. 2016, 16, 4521-4527.

[31] X. Fang, W. Weng, J. Ren, H. S. Peng, Adv. Mater 2016, 28, 491-496.

[32] B. Akinwolemiwa, C. Peng, G. Z. Chen, J. Electrochem. Soc. 2015, 162, A5054-A5059.

[33] K. L. Wang, K. Jiang, B. Chung, T. Ouchi, P. J. Burke, D. A. Boysen, D. J. Bradwell, H. Kim, U. Muecke, D. R. Sadoway, Nature 2014, 514, 348-350.

[34] D. J. Bradwell, H. Kim, A. H. C. Sirk, D. R. Sadoway, J. Am. Chem. Soc. 2012, 134, 1895-1897.

[35] T. Ouchi, H. Kim, B. L. Spatocco, D. R. Sadoway, Nat. Commun. 2016, 7, 10999. 